\title{
ANALISIS SEMIOTIKA BUSANA ADAT KABUPATEN KEBUMEN SERTA RELEVANSINYA TERHADAP MATERI PEMBELAJARAN BAHASA INDONESIA SISWA SMP
}

\author{
Arina Dina Sofiyatun ${ }^{(1)}$, Bagiya ${ }^{(2)}$, Nurul Setyorini ${ }^{(3)}$ \\ Universitas Muhammadiyah Purworejo \\ Pos-el: arinadina399@gmail.com
}

\begin{abstract}
Abstrak
Penelitian ini bertujuan untuk mendeskripsikan (makna yang terkandung dalam busana adat Kabupaten Kebumen dan relevansi kajian semiotik busana adat Kabupaten Kebumen terhadap materi pembelajaran bahasa Indonesia siswa SMP kelas VII. Penelitian ini merupakan penelitian kualitatif. Objek penelitian ini adalah busana adat Kabupaten Kebumen. Fokus penelitian ini adalah kajian semiotika busana adat Kabupaten Kebumen dengan teori Roland Barthes. Sumber data dalam penelitian ini diperoleh dari dokumentasi Peraturan Bupati Kebumen. Dari hasil penelitian ini disimpulkan bahwa hasil temuan semiotika busana adat Kabupaten Kebumen meliputi: busana laki-laki terdapat Ikat kepala, Surjan Ikat Pinggang, Lancingan Bebed Panjen, Celana Komprang, Sandal bandolan. Busana perempuan terdapat Jilbab Warna Krem, Kebaya Kartini, Stagen, dan Kain Jagatan Latar Putih dengan Wiron Mataraman. Relevansi materi pembelajaran bahasa Indonesia pada busana adat Kabupaten Kebumen di kelas VII SMP dapat dilaksanakan sesuai dengan Kompetensi Dasar (KD) mengidentifikasikan informasi dalam teks deskripsi tentang objek yang didengar maupun dibaca.

Kata kunci: Semiotika, busana adat Kabupaten Kebumen, materi pembelajaran
\end{abstract}

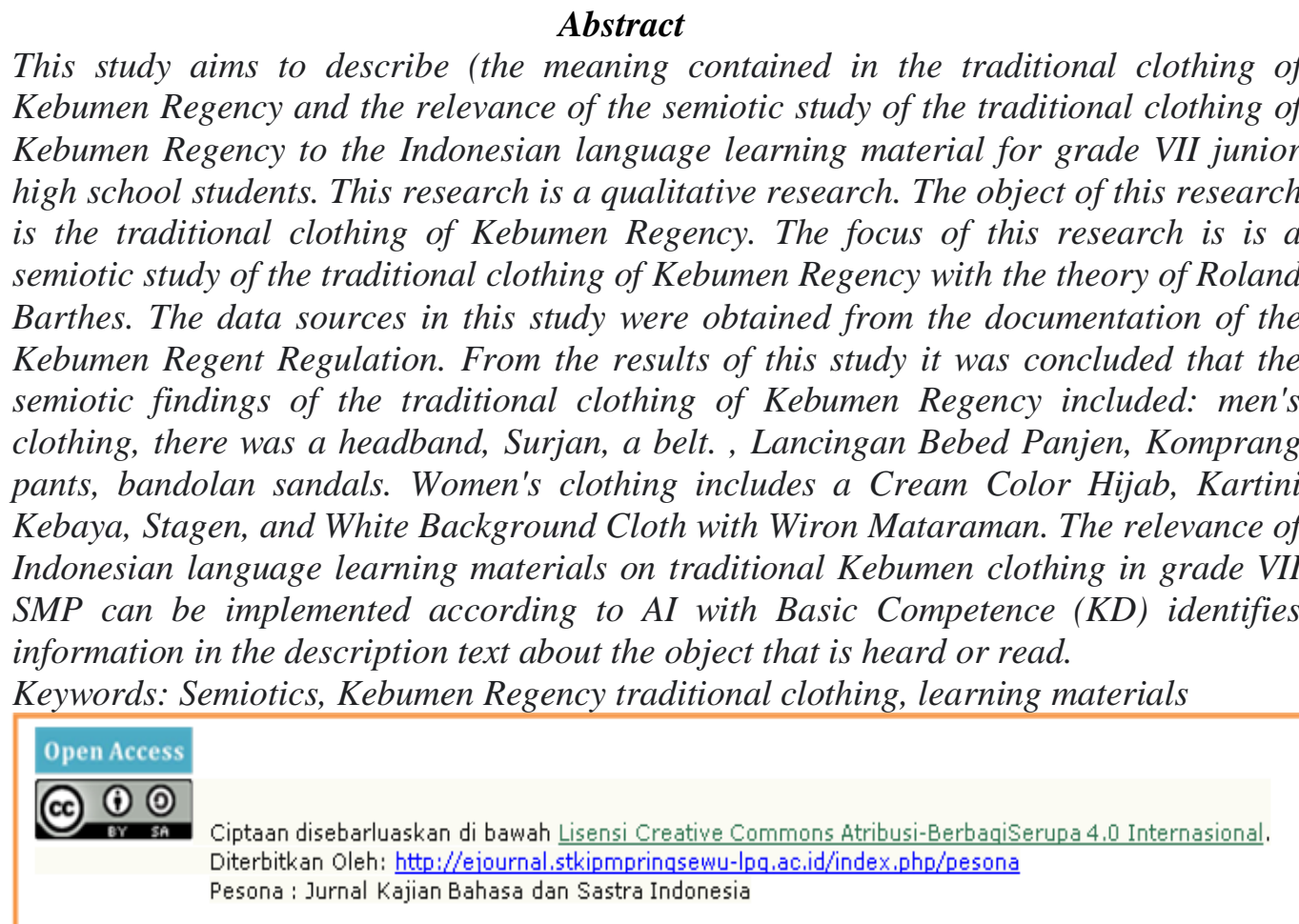





\section{PENDAHULUAN}

Indonesia merupakan negara yang kaya akan budaya. Setiap daerah di Indonesia memiliki ciri khas masingmasing. Budaya merupakan hasil dari olah pikir manusia untuk mengodekan atau membukakan kode dari sesuatu yang hadir di hadapan masyarakat. Dalam kehidupannya, manusia memang menggunakan lambang atau simbol. Sejalan dengan itu, Cassier mengatakan bahwa manusia adalah makhluk bersimbol (Chaer, 2012: 39).

Busana adat merupakan suatu hasil budaya dan simbol yang menandai perkembangan akulturasi daerah. Busana adat memiliki ciri khas tersendiri yang menjadi identitas dan karakter budaya dari suatu kelompok daerah tersebut.Busana bukan hanya sekadar kain melainkan rekam-jejak sejarah, pemikiran, juga keyakinan suatu kelompok sosial dan berfungsi untuk menunjukkan unsur kekentalan budaya masing-masing daerah.

Kabupaten Kebumen merupakan salah satu daerah di antara puluhan Kabupaten di Provinsi Jawa tengah yang memiliki busana adat. Busana adat Kabupaten Kebumen memiliki ciri khas pada motif yang mengangkat keseharian warga. Motif tersebut sebagai simbol yang mengodekan makna atau pesan tertentu. Makna tersebut dapat tersampaikan melalui bahasa.

Bahasa merupakan suatu sistem yang digunakan oleh masyarakat untuk alat komunikasi. Sebagai alat komunikasi, bahasa memiliki proses pertukaran informasi antarindividual melalui sistem simbol, tanda, berinteraksi, dan bertukar informasi (Bagiya, 2017: 3). Bahasa terdiri atas bahasa tulis dan nontulis. Semua kegiatan yang dilakukan oleh manusia tidak lepas dari bahasa. Banyak masyarakat yang menyampingkan bahasa nontulis karena menganggap bahasa tulis lebih penting untuk dikuasai padahal jika dikaji bahasa nontulis memiliki makna yang dalam.

Busana adat Kebumen merupakan wujud komunikasi untuk menceritakan segala hal kearifan lokal yang ada di kabupaten Kebumen dari hasil alam, sejarah, dan lain-lain yang memiliki arti tersendiri. Selain sebagai pakaian khas yang memiliki estetika, busana adat juga memiliki makna simbolik yang terdapat pada motif busana adat. Dikarenakan busana adat ini baru saja diluncurkan, sehingga masih banyak masyarakat yang tidak mengetahui makna atau pesan yang ada dibalik motif. Hal ini membuat peneliti tertarik untuk mengembangkan 
penelitian mengenai busana adat kabupaten Kebumen melalui pendekatan semiotik.

Semiotik merupakan ilmu dan metode analisis untuk mengkaji tandatanda yang terdapat pada suatu objek untuk diketahui makna yang terkandung dalam objek tersebut. Preminger menyampaikan semiotik menganggap bahwa fenomena sosial atau masyarakat dan kebudayaan itu merupakan tandatanda (Kriyantoro, 2014: 265).

Pembelajaran bahasa di kelas sering dirasa jenuh oleh siswa. Seorang pendidik harus jeli dalam memilih metode dan media pembelajaran bahasa agar tidak terkesan membosankan. Pembelajaran bahasa tidak serta melulu menggunakan tulisan sebagai media pembelajaran, sesekali perlu menggunakan media nontulis salah satunya menggunakan busana adat Kebumen untuk menyampaikan materi pembelajaran.

Penelitian terdahulu yang dilakukan oleh Aji dan Bagiya (2019) pada Proseding Seminar Internasional The $9^{\text {th }}$ University Research Colloqium 2019, Universitas Muhammadiyah Purworejo berjudul "Kajian Semiotika Motif Batik Tulis Adi Purwo Khas Purworejo". Persamaan penelitian yang dilakukan Aji, Bagiya dan penelitian ini adalah penelitian termasuk dalam penelitian kualitatif yang bersifat deskriptif, samasama memfokuskan pada penelitian semiotik, teori yang digunakan teori Roland Barthes. Perbedaan penelitian Aji, Bagiya dengan penelitian ini yakni objek penelitian, teknik pengumpulan data, teknik analisis data dan relevansi terhadapat materi pembelajaran. Penelitian Aji dan Bagiya objek penelitiannya adalah batik tulis Adi Purwo, teknik pengumpulan data yang digunakan adalah gabungan dari teknik dokumentasi, wawaancara, dan observasi, teknik analisis data yang dilakukan adalah reduksi data, penyajian data, dan verifikasi, penelitian yang dilakukan oleh Aji dan Bagiya tidak dihubungkan dengan relevansi materi pembelajaran, sedangkan penelitian ini objek penelitiannya adalah busana adat, teknik pengumpulan data yang digunakan adalah teknik baca dan teknik catat, teknik analisis data yang dilakukan pada penelitian ini adalah metode padan referensial dengan teknik dasar daya pilah sebagai pembeda referen, penelitian ini dihubungkan dengan relevansi terhadap materi pembelajaran bahasa Indonesia siswa SMP kelas VII.

Selain penelitian Aji, Bagiya dilakukan penelitian oleh Hidayati, Kadaryati, dan Bagiya. Hidayati, Kadaryati, dan Bagiya meneliti (2015) dengan penelitiannya yang berjudul 
Arina Dina Sofiatun...

"Kajian Semiotik Kumpulan Cerpen

Pilihan Kompas 2012 Laki-Laki

Pemanggul Goni dan Recana Pelaksanaan

Pembelajaran di Kelas VII SMP”.

Penelitian yang dilakukan oleh Hidayati,

Kadaryati, Bagiya dan penelitian ini adalah penelitian yang termasuk penelitian kualitatif, sama-sama meneliti kajian semiotik, dan teknik hasil analisis yang dilakukan adalah teknik informal. Perbedaan penelitian ini dengan penelitian Hidayati, Kadaryati, dan Bagiya terletak pada objek penelitian, fokus penelitian, teknik pengumpulan data, instrumen penelitian, teknik analisis data, dan relevansi terhadapat materi pembelajaran. Objek penelitian Hidayati, Kadaryati, Bagiya adalah Kumpulan Cerpen Pilihan Kompas 2012 Laki-Laki Pemanggul Goni, fokus penelitian berupa kalimatkalimat atau kutipan-kutipan yang diambil dari kumpulan cerpen, teknik pengumpulan data yang digunakan adalah teknik pustaka, instrumen penelitian yang digunakan adalah penulis, pengumpul data, dan buku-buku yang relevan dengan konstruksi penelitian, teknik analisis data yang dilakukan adalah teknik analisis ini, penelitian Hidayati, Kadaryati, dan Bagiya tidak dihubungkan dengan relevansi terhadap materi pembelajaran, sedangkan penelitian ini objek penelitiannya adalah busana adat, fokus penelitian ini berupa analisis semiotika dengan teori Roland Barthes pada motif busana adat Kabupaten Kebumen serta relevansinya terhadap materi pembelajaran bahasa Indonesia siswa SMP kelas VII, teknik pengumpulan data yang digunakan pada penelitian ini adalah teknik baca dan teknik catat, instrumen yang digunakan pada penelitian ini adalah peneliti sendiri dengan menggunakan kertas pencatat data dan alat tulis, teknik analisis data yang dilakukan pada penelitian ini adalah metode padan referensial dengan teknik dasar daya pilah sebagai pembeda referen. Penelitian ini dihubungkan dengan relevansi materi pembelajaran bahasa Indonesia siswa SMP kelas VII, sedangkan penelitian Hidayati, Kadaryati, dan Bagiya dilengkapi dengan rencana pelaksanaan pembelajaran.

Berdasarkan pernyataan di atas, penelitian ini bertujuan mendeskripsikan (1) makna yang terkandung dalam busana adat Kabupaten Kebumen; (2) relevansi kajian semiotik busana adat Kabupaten Kebumen terhadap materi pembelajaran bahasa Indonesia siswa SMP kelas VII.

\section{METODE PENELITIAN}


Penelitian ini termasuk dalam penelitian kualitatif yang bersifat deskriptif. Objek penelitian ini terbagi menjadi objek formal dan objek material. Objek formal dalam penelitian ini berupa analisis semiotika Motif Busana Adat khas Kebumen serta Relevansinya Materi Pembelajaran di SMP. Objek material merupakan objek yang akan diteliti. Objek material pada penelitian ini berupa Motif Busana Adat. Fokus pada penelitian ini berupa analisis semiotika dengan teori Roland Barthes pada motif Busana Adat Kebumen serta Relevansi Materi Pembelajaran Bahasa Indonesia Siswa SMP kelas VII. Teknik pengumpulan data yang digunakan dalam penelitian ini adalah teknik baca dan teknik catat (Sudaryanto, 2015: 205). Arikunto mendefinisikan instrumen penelitian merupakan alat bantu bagi penulis dalam mengumpulkan data (Pangesti, Bagiya, Kadaryati, 2019: 86).

Instrumen yang digunakan dalam penelitian ini adalah peneliti sendiri dengan menggunakan kartu pencatat data dan alat tulis. Teknik penyajian analisis data yang digunakan dalam penelitian ini sejalan dengan pendapat Sudaryanto yang mengemukakan bahwa teknik penyajian informal adalah perumusan dengan katakata biasa (Rahmawati, Bagiya, Setyorini, 2017: 747). Tahapan pada penelitian ini yakni membaca dokumen Perbup Nomor 35 Tahun 2017, berikutnya mengidentifikasikan semantik Roland Barthes, selanjutnya mencatat data berupa kalimat yang diperlukan pada kartu data, kemudian mengklasifikasikan semantik Roland Barthes.

\section{HASIL DAN PEMBAHASAN}

Ada dua hasil penelitian ini yaitu Analisis Semiotika pada Busana Adat Kabupaten Kebumen serta Relevansinya terhadap Materi Pembelajaran Bahasa Indonensia Siswa SMP Kelas VII.

\section{Analisis Semiotika pada Busana Adat Kabupaten Kebumen}

Dalam penelitian ini telah ditemukan busana adat Kabupaten Kebumen yang meliputi busana lakilaki dan busana perempuan. Busana adat Kabupaten Kebumen merupakan busana yang memiliki model tersendiri digunakan pada acara khusus memiliki nuansa kedaerahan, warna dan corak spesifik yang diakui sebagai ciri khas daerah Kebumen. Busana adat ini merupakan wujud komunikasi untuk menceritakan segala hal kearifan lokal yang ada di Kebumen dari hasil alam, sejarah, dan lain-lain yang memiliki arti sendiri. Berikut ini disajikan pembahasan masing-masing motif 
busana adat Kabupaten Kebumen yang

ditemukan.

\section{a) Ikat Kepala}

Ikat kepala ini secara denotasi merupakan gambaran dari motif modang yang digambarkan bentukbentuk parang tuding. Tuding memiliki makna menunjuk. Selanjutnya, ikat kepala ini secara konotasi merupakan gambaran motif modang memiliki makna bahwa orang yang memakai diharapkan dapat menunjukkan hal-hal baik dan menimbulkan kebaikan.

\section{b) Surjan}

Surjan merupakan busana atasan resmi adat Jawa yang digunakan untuk kaum laki-laki. Surjan secara denotasi merupakan gambaran baju jas laki-laki Jawa berkerah tegak, berlengan panjang terbuat dari bahan lurik. Selanjutnya, secara konotasi surjan merupakan gambaran kerah yang memiliki enam kancing. Gambaran tersebut melambangkan Rukun Iman yang jumlahnya enam dan dua enam kancing dibagian kanan kiri melambangkan dua kalimat syahadat.

\section{c) Ikat Pinggang}

Ikat pinggang pada busana adat Kabupaten Kebumen dikenal dengan sebutan sabuk kopel. Secara denotasi dapat diketahui bahwa kopel dalam Kamus Besar Bahasa Indonesia bermakna bergandengan saling berhubungan. Selanjutnya, secara konotasi sabuk memiliki makna agar manusia menggunakan badannya untuk bekerja sungguh-sungguh, jangan sampai pekerjannya tidak menghasilkan atau tidak menguntungkan (buk).

\section{d) Lancingan Bebed Panjen}

\section{Lancingan}

Bebed

Panjenmerupakan gambaran kain jarit dengan motif batik jagatan latar putih yang dikenakan menutupi seluruh tubuh. Secara konotasi gambaran tersebut memiliki makna bahwa manusia harus ubed yekni tekun dan rajin dalam bekerja mencari rezeki.

\section{e) Celana Komprang}

Celana komprang merupakan gambaran celana bentuknya longgar yang panjangnya di atas mata kaki. Secara konotasi gambaran tersebut melambangkan langkah yang tutug (selesai), walaupun celana itu longgar 
tapi ada batasannya, ada ukurannya yang bermakna tata tertib. Dalam peribahasa Jawa disebutkan "tata, tatag, dan tutug" yang bermakna hidup itu harus sesuai aturan, berani dalam kebaikan, dan selesai dalam mengemban amanat Tuhan.

\section{f) Sandal Bandolan}

Sandal bandolan merupakan sandal yang terbuat dari ban bekas. Secara konotasi gambaran tersebut memiliki makna bahwa manusia harus menghargai apapun dan siapapun walaupun hanya berupa barang bekas.

\section{g) Jilbab Warna Krem}

Jilbab yang digambarkan dengan warna krem secara konotasi memiliki makna kelembutan dan klasik.

\section{h) Kebaya Kartini}

Kebaya merupakan manifestasi dan mozaik histori busana perempuan Indonesia dengan rona pesona estetika yang membumi. Secara konotasi kebaya memiliki ruang gerak yang mampu menampilkan keanggunan dan kesopanan yang menggambarkan perempuan dengan tipikal lemah lembut, sopan, tenang, damai, dan penuh kasih.

\section{i) Stagen}

Stagen merupakan ikat pinggal tradisional masyarakat Jawa yang terbuat dari tenun. Secara konotasi stagen yang berbentuk panjang dan membentuk tubuh bermakna bahwa wanita Jawa adalah sosok yang mampu menyesuaikan diri, dan melambangkan kesabaran seorang wanita Jawa.

\section{j) Kain Jagatan Latar Putih dengan Wiron Mataraman}

Kain Jagatan Latar Putih merupakan kain jarik dengan motif jagatan latar putih. Kain jarik merupakan kain panjang yang dikenakan untuk menutupi tubuh sepanjang kaki. Gambaran tersebut secara konotasi memiliki makna bahwa seseorang jangan mudah iri terhadap orang lain, karena iri hati akan menimbulkan rasa emosional, grusagrusu dalam menanggapi segala masalah. Selanjutnya, motif jagatan latar melambangkan ungkapan cinta, keindahan dalam keragaman dunia.

\section{Relevansinya terhadap Materi}

\section{Pembelajaran Bahasa Indonensia Siswa SMP Kelas VII}

Penyusunan materi pelajaran bahasa Indonesia di SMP disesuaikan dengan kurikulum. Kurikulum adalah 
rambu-rambu yang menjadi pedoman guru untuk menentukan pokok-pokok yang akan diajarkan kepada siswa. Kurikulum yang berlaku sekarang adalah kurikulum 2013. Pada pembelajaran bahasa Indonesia yang dikaitkan dengan kurikulum 2013 ada salah satu kompetensi yang harus dikuasai oleh siswa SMP adalah KD 3.1 Mengidentifikasikan informasi dalam teks deskripsi tentang objek yang didengar maupun dibaca. Di dalam kompetensi dasar tersebut memuat kompetensi untuk menjelaskan isi teks deskripsi objek berupa busana adat.

\section{SIMPULAN}

Berdasarkan pembahasan di atas dapat dibuat simpulan bahwa (1) kajian semiotika pada busana adat Kabupaten Kebumen terdiri atas busana laki-laki terdapat Ikat kepala memiliki makna hubungan yang harus dijaga manusia, Surjan memiliki makna pelita/penerang, Ikat Pinggang memiliki makna manusia menggunakan badannya untuk bekerja sungguh-sungguh, Lancingan Bebed Panjenmemiliki makna manusia harus tekun dan rajin dalam bekerja mencari rezeki, Celana Komprang memiliki makna hidup itu harus sesuai aturan,
Sandal bandolanmemiliki makna manusia harus menghargai apapun dan siapapun; busana perempuan terdapat Jilbab Warna Krem memiliki makna kelembutan dan klasik, Kebaya Kartini memiliki makna perempuan dengan tipikal lemah lembut, Stagenmemiliki makna perempuan yang mampu menyesuaikan diri, Kain Jagatan Latar Putih dengan Wiron Mataraman memiliki makna jangan mudah iri terhadap orang lain, (2) relevansi terhadap materi pembelajaran bahasa Indonesia dapat dikaitkan dengan KD 3.1 pada materi teks deskripsi kelas VII SMP. Materi tersebut memuat kompetensi dasar untuk menjelaskan isi teks deskripsi objek berupa busana adat.

\section{DAFTAR PUSTAKA}

Aji, Diki Bayu, Bagiya. 2019. "Kajian Semiotika Motif Batik Tulis Adi Purwo Khas Purworejo". Proseding Seminar Internasional The ${ }^{\text {th }}$ University Research Colloqium 2019. Universitas Muhammadiyah Purworejo.

Bagiya. 2017. Linguistik Umum. Yogyakarta: Jumat Publishing

Chaer, Abdul. 2015. Linguistik Umum. Jakarta: Rineka Cipta.

Hidayati, Fatma, Kadaryati, dan Bagiya. 2015. "Kajian Semiotik Kumpulan Cerpen Pilihan Kompas 2012 Laki-Laki Pemanggul Goni dan 
Rencana Pelaksanaan

Pembelajaran di Kelas VII SMP”. Jurnal Surya Bahtera. Universitas Muhammadiyah Purworejo. Vol. 3, No. 21, 1-8. Diperoleh dari http://ejournal.umpwr.ac.id (diund uh 21 Oktober 2019).

Kriyantono, Rachmat. 2014. Teknis Praktis Riset Komunikasi Disertai Contoh Praktis Riset Media, Public Relations, Advertising, Komunikasi Organisasi, Komunikasi Pemasaran. Jakarta : Prenada Media

Pangesti, Azizah Diah, Bagiya, dan Kadaryati. 2019. "Analisis Tindak Tutur Direktif dan Ekspresif pada Film My Idiot Brother Karya Alyandran dan Skenario Pembelajarannya di Kelas XI SMA". Jurnal Surya Bahtera. Universitas Muhammadiyah Purworejo. Vol. 07, No. 02, 82-89.

Rahmawati, Dian, Bagiya, dan Nurul Setyorini. 2017. "Peningkatan Keterampilan Menulis Puisi dengan Model Kancing Gemerincing dan Media Poster pada Siswa Kelas VII E SMP Negeri 36 Purworejo Tahun Pelajaran 2016/2017".Jurnal Surya Bahtera. Universitas Muhammadiyah Purworejo. Vol. 5, No. 49, 745-752.

Sudaryanto. 2015. Metode Dan Aneka Teknik Analisis Bahasa:

Pengantar Penelitian Wahana

Kebudayaan Secara Linguis.

Yogjakarta: Duta Wacana

University Press. 